\title{
O Internato Médico após as Diretrizes Curriculares Nacionais de 2014: um Estudo em Escolas Médicas do Estado do Rio de Janeiro
}

\author{
The Medical Intern after the National \\ Curricular Guidelines of 2014: a Study in \\ Medical School of Rio de Janeiro State
}

Patrícia Tavares da Silva Cândido ${ }^{I}$

Nildo Alves BatistaII

\section{PALAVRAS-CHAVE}

- Educação Médica.

- Escolas Médicas.

- Currículo.

- Internato e Residência.
${ }^{I}$ Faculdade de Medicina de Petrópolis, Petrópolis, Rio de Janeiro, Brasil.

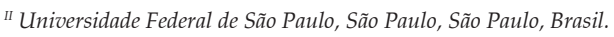

Instituídas em 2014, as Diretrizes Curriculares Nacionais (DCN) do Curso de Graduação em Medicina contêm várias recomendações, especialmente para o internato médico. Apesar do reconhecimento da necessidade de mudanças no que se refere à capacitação profissional para atender às demandas da comunidade, muitos consideraram pouco democrática a instituição dessas DCN. Seu processo de implantação ainda é pouco estudado. Objetivou-se analisar o internato médico em escolas médicas do Estado do Rio de Janeiro após a instituição das DCN de 2014, sob a ótica dos coordenadores de curso e de internato. Em 2016, o Estado do Rio de Janeiro possuía 19 cursos de Medicina, em 15 escolas médicas. Destes, nove cursos participaram da pesquisa. A população de estudo foi representada por 13 participantes - nove coordenadores de curso e quatro coordenadores de internato. Trata-se, assim, de uma amostragem do universo das escolas, sem intenção de generalização dos resultados para todo $o$ Estado. Foram utilizadas abordagens qualitativas e quantitativas. As questões abertas foram submetidas à análise de conteúdo, e a escala atitudinal foi avaliada por análise estatística. Na visão dos coordenadores, todas as escolas médicas estão em processo de adequação às determinações das DCN de 2014. A maioria está de acordo com a inclusão obrigatória, no internato, das áreas de Urgência e Emergência, Atenção Básica e Saúde Mental. Muitas são as dificuldades encontradas no processo de implantação elou reestruturação dessas atividades no internato: escassez de cenários; precariedade dos cenários existentes na Emergência do Sistema Único de Saúde; falta de docentes/preceptores e o prazo estabelecido para a implantação das Diretrizes. Entretanto, algumas estratégias têm sido planejadas, como a diversificação dos cenários de prática, a criação de estágios eletivos, o estabelecimento de convênios e parcerias, o desenvolvimento de atividades integradas com outras áreas do internato e a utilização de laboratórios de simulação realística. As escolas médicas vivem um momento de transformação curricular, impulsionado pelas DCN. Esse momento deve ser encarado como uma oportunidade para revisitar o internato médico e, possivelmente, encontrar estratégias para aprimorar a formação médica nesse espaço privilegiado da graduação. Acredita-se que a divulgação dos resultados desta pesquisa possa auxiliar as escolas médicas no processo de apropriação e implantação das determinações das DCN de 2014. 


\section{KEY-WORDS}

- Medical Education.

- Medical Schools

- Curriculum.

- Internship and Residency.

\begin{abstract}
Established in 2014, the National Curricular Guidelines (NCG) for the Undergraduate Medical Course contain several recommendations, especially for Medical Internship. Despite the recognition of the need for changes, in terms of professional training to meet the demands of the community, instituting these NCG was considered by many to be rather undemocratic. Yet, few studies have investigataed the implementation process. The objective was to analyze the Medical Internship in Medical Schools of the State of Rio de Janeiro, after institution of the NCG of 2014, according to the Course and Internship Coordinators. In 2016, the State of Rio de Janeiro had 19 medical courses, in 15 Medical Schools. Of these, nine courses participated in the research. The study population was represented by 13 participants, nine Course Coordinators and four Internship Coordinators. It is thus a sample of the universe of schools, with no intention of generalizing the results to represent the whole State. Qualitative and quantitative approaches were used. The answers of the open-ended questions were submitted to content analysis, the scale was evaluated by statistical analysis. In the view of the Coordinators participating in the research, all Medical Schools are in the process of adapting to the NGC's determinations of 2014. The majority agrees with the mandatory inclusion of Urgency and Emergency, Primary Care and Mental Health in the Internship areas. Many difficulties were encountered in the process of implantation and/or restructuring of these activities in Internship: scarcity of practical scenarios; precariousness of existing scenarios in emergency care of the Unified Health System; lack of teachers/preceptors; and the deadline established for the implementation of the Guidelines. However, some strategies have been planned, such as the diversification of practice scenarios, the creation of elective internships, the establishment of agreements and partnerships, development of integrated activities with other Internships areas and the use of realistic simulation laboratories. The Medical Schools live a moment of curricular transformation, driven by the NCG. We must see this moment as an opportunity to revisit the Medical Internship and, possibly, to find strategies for the improvement of medical training in this privileged undergraduate space. It is believed that dissemination of the results of this research can help Medical Schools in their appropriation and implementation of the NCGs of 2014.
\end{abstract}

Recebido em: 6/12/18

Aceito em: 8/1/19

\section{INTRODUÇÃO}

O internato médico representa uma etapa primordial na formação médica, na qual o estudante, por meio do treinamento em serviço, aprimora, consolida e dá um novo significado ao seu conhecimento. Desempenha, assim, um importante papel no aperfeiçoamento das técnicas e habilidades médicas e contribui para a profissionalização do estudante por intermédio do desenvolvimento progressivo de responsabilidade e de autonomia na prática da medicina.

Assim, o internato aproxima o "aprendiz" do "indivíduo/ comunidade", com suas especificidades, e aprimora o desenvolvimento da relação médico-paciente. Por essa razão, espera-se que o estudante se aproprie do "ser médico" e do "saber tratar" e se conscientize de que a sua atuação deve abranger muito mais que o conhecimento das patologias, direcionando-a à promoção integral e humana do cuidado.
Como etapa final do curso de graduação, o internato foi regulamentado pela primeira vez no Brasil pela Resolução ${ }^{\circ}$ 8 de 1969, do Conselho Federal de Educação (CFE), que o tornou obrigatório como período especial de aprendizagem ${ }^{1}$. A Resolução n 9, em 1983, o definiu como um período obrigatório de ensino-aprendizagem, durante o qual o estudante deve receber um treinamento intensivo, contínuo, sob a supervisão docente e em instituições de saúde vinculadas ou não à escola médica². Essa Resolução representou a única orientação para o internato até a instituição das Diretrizes Curriculares Nacionais (DCN) para o Curso de Graduação em Medicina de $2001^{3,4}$.

Nestas DCN, o Sistema Único de Saúde (SUS) aparece como o principal norteador do processo, com o objetivo de formar um profissional com capacidade para atuar em conformidade com o sistema de saúde vigente, fortalecendo e per- 
petuando seus princípios, de acordo com as necessidades do cidadão, da família e da comunidade ${ }^{4}$.

As DCN estabeleciam uma carga horária mínima para o internato de $35 \%$ da carga horária total do curso, incluindo os aspectos essenciais de Clínica Médica, Cirurgia, Pediatria, Ginecologia/Obstetrícia, com atividades eminentemente práticas. Determinavam a inclusão obrigatória da Saúde Coletiva e a restrição das atividades teóricas a no máximo $20 \%$ da carga horária total. Por essas diretrizes, 25\% da carga horária total do internato poderiam ser realizados fora da unidade federativa, preferencialmente nos serviços do SUS, a critério do colegiado do curso ${ }^{4}$.

Por ocasião da instituição das DCN, a Associação Brasileira de Educação Médica (Abem) realizou uma ampla discussão em suas regionais, tendo, em 2008, desenvolvido o projeto "Contribuição para a formação do médico de acordo com as necessidades da sociedade" e em 2012 o projeto "Abem 50 anos - 10 anos de $\mathrm{DCN}^{\prime \prime}$, com um subprojeto direcionado ao internato que culminou com a formulação de diretrizes nacionais para o mesmo².

Apesar destas discussões, um estudo realizado em 2014 em escolas médicas públicas da Região Nordeste concluiu que houve incorporação parcial das recomendações das DCN de 2001. Como desafios para sua implementação, os gestores pontuaram: resistência docente, discente e de técnicos administrativos; entraves na relação ensino-serviço; falta de sintonia entre a gestão acadêmica e a gestão administrativa; falta de reconhecimento e apoio à preceptoria; e despreparo do gestor acadêmico para a sua prática ${ }^{5}$.

A despeito da implementação parcial das DCN de 2001, em 2013 é promulgada a Lei no 12.871 e instituído o Programa Mais Médicos. Esse programa previa a formação de recursos humanos na área médica para o SUS, com os seguintes objetivos: diminuir a carência de médicos nas regiões prioritárias; fortalecer a Atenção Básica, aprimorar a formação médica, orientar a formação para profissionais capazes de atuar nas políticas públicas de saúde do País e na organização e no funcionamento do sistema de saúde, estimular a realização de pesquisas aplicadas e aumentar a experiência prática durante o processo de formação, a fim de ampliar a inserção do graduando em cenários de prática do SUS6 .

Esta Lei determina, em seu primeiro parágrafo do Art. $4^{\circ}$, do Capítulo III, que 30\% da carga horária do internato sejam desenvolvidos nas áreas de Atenção Básica e em serviços de Urgência e Emergência do SUS, respeitando-se a duração mínima de dois anos ${ }^{6}$. Houve, assim, a necessidade de adaptação de novas DCN, cujo processo culminou na Resolução do Conselho Nacional de Educação (CNE) da Câmara de Educação Superior (CES), de 20 de junho de $2014^{7}$.
As DCN de 2014 estabeleceram que a preceptoria, exercida por profissionais do serviço de saúde, contaria com a supervisão dos próprios docentes das instituições de ensino superior (IES) e que a carga horária do internato representaria, no mínimo, 35\% da carga horária total do curso. Desse percentual, no mínimo 30\% deveriam estar voltados à Atenção Básica e aos serviços de Urgência e Emergência do SUS7.

Essa nova versão determina que as atividades voltadas à Atenção Básica sejam desenvolvidas no âmbito da Medicina Geral de Família e Comunidade, considerando obrigatória a inclusão da área de Saúde Mental ${ }^{7}$ e que, com força de Lei, o prazo para a implantação progressiva do internato seja 31 de dezembro de 2018.

Apesar do reconhecimento da necessidade de mudanças no que se refere à capacitação profissional para atender às demandas da comunidade, a elaboração e a instituição das DCN de 2014 foram consideradas, por muitos, pouco democráticas, e seu processo de implantação ainda é pouco estudado.

Este artigo tem como objetivo analisar o internato médico, após a instituição das DCN de 2014, em escolas médicas do Estado do Rio de Janeiro na perspectiva dos coordenadores de curso e coordenadores de internato, partindo das seguintes indagações: como estão atualmente planejados os estágios curriculares obrigatórios dos cursos de graduação em Medicina do Estado do Rio de Janeiro no tocante às determinações das DCN de 2014? Qual a opinião/avaliação desses coordenadores/diretores sobre as determinações das DCN a respeito do internato médico? Que estratégias e dificuldades eles apontam para sua operacionalização?

\section{MÉTODOS}

Optou-se por uma pesquisa exploratória, descritiva, com a utilização de abordagens qualitativas e quantitativas. Partimos do pressuposto de que as pesquisas exploratórias têm o propósito de conhecer melhor o objeto a ser estudado e têm como objetivo principal tornar mais explícito o estudo de um problema ou construir hipóteses ${ }^{8}$. Já as abordagens qualitativas se aplicam ao estudo das relações, das representações, das percepções, das opiniões que resultam do modo como o sujeito pensa, sente, insere-se no contexto social e na maneira como se relaciona?.

A pesquisa foi realizada no Estado do Rio de Janeiro, que, no momento da coleta dos dados, possuía 19 cursos de Medicina em 15 escolas médicas (quatro escolas tinham dois cursos). Os dados foram obtidos no site emec.mec.gov.br, no dia 28 de março de 2016. Dos 19 cursos, 14 pertenciam a instituições privadas e cinco a instituições públicas. Somente um curso de instituição pública não está localizado na Região Me- 
tropolitana. Foram incluídas escolas que tinham, no mínimo, uma turma de alunos formados no final do ano de 2016, o que levou à exclusão de dois cursos.

Os 17 coordenadores de curso foram contatados por meio dos dados disponíveis na página http://emec.mec.gov.br/, e os coordenadores de internato foram identificados por meio da indicação dos coordenadores de curso. Dos 17 coordenadores convidados a participar da pesquisa, nove responderam ao instrumento de pesquisa ( $53 \%$ do universo). Trata-se, assim, de uma amostragem do universo das escolas, sem intenção de generalização dos resultados para todo o Estado.

No primeiro momento da coleta de dados, o instrumento de pesquisa foi enviado por e-mail, em formato eletrônico, em única etapa. Nos casos em que não houve resposta em até 15 dias, foi realizada nova tentativa, com novo envio. Após mais 15 dias, a pesquisadora fez contato telefônico com aqueles que não haviam enviado o instrumento respondido, formalizando o convite e reforçando o cuidado na preservação do anonimato. A não resposta após o contato telefônico foi considerada recusa.

Alegando não haver o cargo na sua escola, quatro coordenadores de curso não indicaram o coordenador de internato. Numas das escolas, o coordenador de internato foi excluído por participação direta nesta pesquisa. Desse modo, quatro coordenadores de internato responderam ao instrumento de pesquisa enviado.

A população total do estudo foi, assim, representada por 13 participantes, dos quais nove coordenadores de curso e quatro coordenadores de internato (quatro de instituições públicas e nove de instituições privadas).

$\mathrm{O}$ instrumento de produção dos dados foi composto por um questionário com perguntas fechadas (Quadro 1) e abertas (Quadro 2) e uma escala atitudinal do "tipo Likert"10,11 (Quadro 3). O processo de construção desse instrumento se deu em constante diálogo com os objetivos da pesquisa.

\section{$\begin{array}{lll}2 & \text { QUADro } 1\end{array}$ \\ Instrumento de produção de dados - questões fechadas \\ 1. A carga horária do internato médico representa no mínimo $35 \%$ da carga horária total do curso?

$$
\square \operatorname{sim} \quad \square \text { não }
$$

2. A carga horária semanal das atividades do internato representa:

$$
\square \text { até } 40 \text { horas } \square \text { mais de } 40 \text { horas }
$$

3. O internato médico possui atividades na área de Urgência e Emergência?

$$
\square \text { até } 12 \text { horas por dia } \quad \square \text { mais de } 12 \text { horas por dia }
$$

4. O internato médico possui atividades na área de Urgência e Emergência?

$$
\square \operatorname{sim} \quad \square \text { não }
$$

5. As atividades práticas de observação/assistência na área de Urgência e Emergência são desenvolvidas somente em cenários do SUS?

$$
\square \operatorname{sim} \quad \square \text { não }
$$

6. Existem atividades desenvolvidas na área de Urgência e Emergência em ambientes controlados - atividades de simulação?
$\square \operatorname{sim}$
$\square$ não

7. No internato médico, as atividades de Atenção Básica são desenvolvidas na área de Medicina Geral da Família e Comunidade?
$\square \operatorname{sim}$
$\square$ não

8. A carga horária atual das atividades de Atenção Básica e Urgência e Emergência, somadas, representa no mínimo 30\% da carga horária total do internato médico, conforme preconizado nas DCN de 2014?
$\square \operatorname{sim}$
$\square$ não

9. A carga horária atual destinada às atividades de Atenção Básica predomina sobre a carga horária atual destinada às atividades de Urgência e Emergência?
$\square \operatorname{sim}$
$\square$ não

10. O internato médico possui atividades na área de Saúde Mental?
$\square \operatorname{sim}$
$\square$ não

11. O internato atual prevê estágio fora da IES, representando até $25 \%$ da carga horária total estabelecida?

$\square \operatorname{sim} \quad \square$ não

12. Como é realizada a supervisão dos estudantes durante as atividades práticas do internato médico? (O Sr.(a) poderá marcar mais de uma alternativa)

$\square$ somente docentes da instituição

$\square$ médicos/preceptores que atuam nos cenários de prática

$\square$ médicos/preceptores que atuam nos cenários de prática, supervisionados por docente da instituição 


\section{QUADRO 2}

Instrumento de produção de dados - questões abertas

1. Quais foram as principais modificações realizadas, ou que estão sendo realizadas no internato médico, a fim de adequar a carga horária das diferentes áreas obrigatórias ao que está preconizado nas DCN de 2014?

2. Que cenários e estratégias têm sido utilizados ou estão sendo planejados no internato médico para o ensino da Atenção Básica com vistas às recomendações das DCN 2014?

3. Que cenários e estratégias têm sido utilizados ou estão sendo planejados no internato médico para o ensino da Urgência e Emergência com vistas às recomendações das DCN 2014?

4. Com a inclusão da área de Saúde Mental junto às demais áreas já obrigatórias no internato médico, quais são as principais atividades que estão sendo desenvolvidas nesta área?

5. Este espaço é livre para que o Sr.(a) possa registrar qualquer informação que julgue complementar:

A escala atitudinal foi construída com base em três dimensões: determinações gerais e legais das DCN de 2014, recomendações das mesmas para a Atenção Básica e Urgência e Emergência no internato e dificuldades/sugestões na operacionalização de suas determinações no internato. Para cada uma das dimensões, foram elaboradas de seis a oito assertivas. A escala ficou composta por 21 assertivas (6 para a primeira dimensão; 7 para a segunda; 8 para a terceira). Para cada assertiva, as opções de resposta foram: concordo totalmente, inclinado a concordar, inclinado a discordar e discordo totalmente.

As respostas às questões abertas foram submetidas à análise de conteúdo, na modalidade análise temática ${ }^{12}$. Partiu-se da definição de dois núcleos direcionadores: adequação do internato médico às DCN de 2014 e estratégias utilizadas e/ou planejadas para essa adequação.

As questões fechadas foram tabuladas e apresentadas em percentuais. Foram utilizados os seguintes recursos: gráficos de barras, planilha eletrônica MS-Excel, em sua versão do MS-Office 2010 para a organização dos dados, e o pacote estatístico IBM SPSS (Statistical Package for Social Sciences), em sua versão 23.0 para a obtenção dos resultados.

A média de cada uma das assertivas da escala teve sua análise baseada em três intervalos de pontuação - de 1 a 1,99 pontos: a percepção era negativa e mudanças de curto prazo deviam ser adotadas; de 2,00 a 2,99 pontos: revelava aspectos a serem melhorados; e de 3,00 a 4,00 pontos: a percepção era positiva e podia ser potencializada, mas, em princípio, o objeto ou situação pesquisada se encontrava numa zona de conforto ${ }^{13}$.

Esta pesquisa obedeceu aos princípios da Resolução 466/2012, sendo aprovada pelo Comitê de Ética em Pesquisa de Seres Humanos da Universidade Federal de São Paulo sob o $\mathrm{n}^{\circ}$ 1.727.490 em 15 de setembro de 2016.

\section{RESULTADOS E DISCUSSÃO}

Os resultados da pesquisa evidenciam que, sob a ótica dos coordenadores de curso e coordenadores de internato, todas as escolas médicas representadas estavam em movimento para adequação às DCN de 2014. Entretanto, não houve um consenso quanto ao fato de ter havido um avanço significativo para o funcionamento dos cursos de graduação.

É importante enfatizar que, em 2015, no VI Fórum de Ensino Médico, que contou com ampla participação de professores, diretores, coordenadores de curso, preceptores, conselheiros e gestores, foram analisadas as implicações da Lei $n^{\circ}$ 12.871 na formação médica. Uma das conclusões do fórum foi que o cumprimento dessa Lei acarretaria intensas demandas de infraestrutura de ensino e de serviço, bem como a necessidade de contratar e capacitar professores e preceptores. Esse fato culminou na elaboração coletiva de um documento que propunha alterações emergenciais com o objetivo de redução de danos ao ensino médico ${ }^{14}$.

Observa-se que a opinião dos coordenadores se mostrou em consonância com as discussões do fórum, evidenciando que somente $15,4 \%$ deles concordaram totalmente com a afirmação de que a lei significou um avanço significativo para o funcionamento dos cursos de graduação em Medicina (30,8\% discordaram).

A maioria dos coordenadores (92,3\%) reconheceu o Contrato Organizativo de Ação Pública Ensino-Serviço (Coapes) ${ }^{15}$ com as Secretarias Municipais e Estaduais de Saúde como a opção mais adequada à garantia de campos de prática de qualidade para os estudantes no internato. Contudo, apontaram dificuldades para a consolidação de parcerias com os gestores, sendo que a maioria deles $(76 \%)$ discorda de que o Coapes tem se mostrado um meio simples para a pactuação de parcerias e aproximação ensino-serviço-comunidade.

Esta aproximação, principalmente no nível da Atenção Básica, apresenta-se como estratégica para superar uma formação médica tradicional, baseada no modelo flexneriano, hospitalocêntrico, com conteúdos descontextualizados e fragmentados, e cujo principal objetivo é a formação para a doença e não para o atendimento das necessidades do paciente ${ }^{16}$. 


\section{QuAdro 3}

\section{Instrumento de produção de dados - assertivas para cada dimensão estudada}

(A21) A elaboração das DCN de 2014 a partir da Lei do Mais Médicos foi um avanço significativo para o funcionamento dos cursos de graduação em Medicina.

(A11) Frente ao cenário atual, com a evidente falta de recursos humanos, a obrigatoriedade de a preceptoria no internato médico ser exercida por profissionais do serviço de saúde com supervisão dos docentes próprios da instituição de educação superior é impossível de cumprir.

Dimensão 1:

Determinações gerais e legais das DCN de 2014

\section{Dimensão 2:}

Recomendações das DCN de 2014 para a Atenção Básica e Urgência e Emergência no internato médico

\section{Dimensão 3:}

Dificuldades/sugestões na operacionalização das determinações das DCN de 2014 no internato médico
(A6) O Contrato Organizativo de Ação Pública Ensino-Serviço (Coapes) com as Secretarias Municipais e Estaduais de Saúde é a opção mais adequada para a garantia de aumento da oferta de campos de prática de qualidade para os estudantes no internato.

(A1) A inclusão da área de Saúde Mental no internato médico deve ser obrigatória, considerando a progressiva reinserção de pacientes com doenças psiquiátricas na sociedade e também no atendimento médico.

(A17) Os períodos de plantão de até 12 horas diárias, respeitando o limite de 40 horas semanais, são adequados para propiciar o rendimento no aprendizado e evitar a exaustão do aprendente.

(A12) Dado o grande volume de modificações contidas nas DCN de 2014 no tocante ao internato médico, o prazo-limite de 31 de dezembro de 2018 para a adequação completa do internato médico é insuficiente.

(A7) A Atenção Básica deve fazer parte do núcleo central das atividades discentes desenvolvidas no internato médico, visto que tem capacidade para resolver $80 \%$ dos problemas de saúde da população.

(A2) As atividades voltadas para a Atenção Básica deverão ser realizadas no âmbito da Medicina Geral de Família e Comunidade.

(A13) O treinamento do interno na área de Saúde Mental no internato médico deve ser realizado nos cenários de Atenção Básica.

(A18) O treinamento do interno em cenários de Atenção Básica e Urgência e Emergência deve representar, no mínimo, $30 \%$ da carga horária total do internato médico, o que significa pelo menos seis meses nestes cenários.

(A8) As atividades de Urgência e Emergência devem ter destaque no internato médico, pois grande parte dos egressos inicia suas atividades profissionais nesses campos de prática.

(A3) O desenvolvimento de atividades em ambiente pré-hospitalar durante o internato é fundamental para o desenvolvimento das competências para atuação na área de Urgência e Emergência.

(A14) As atividades em ambientes controlados (laboratórios de simulação) são fundamentais no desenvolvimento das atividades de Urgência e Emergência no internato médico.

(A19) É necessário aumentar o tempo de internato médico para além dos dois anos obrigatórios, tendo em vista as determinações das DCN de 2014.

(A9) A implantação de, no mínimo, 30\% da carga horária total do internato médico em Urgência e Emergência/Atenção Básica é uma tarefa difícil de ser operacionalizada no internato médico de minha escola.

(A4) A precariedade dos cenários de Urgência e Emergência no âmbito do SUS e a não fixação de profissionais nos serviços de urgência são desafios ao desenvolvimento de atividades docentes nesse contexto.

(A15) O desenvolvimento das atividades do internato em cenários de Urgência e Emergência restritos aos serviços públicos é impossível de ser colocado em prática no cotidiano da minha escola.

(A20) O tempo de estágio nos cenários de Medicina de Família e Comunidade preconizados nas DCN de 2014 é excessivo, podendo ser reduzido.

(A10) A cultura já enraizada de um internato médico hospitalocêntrico impossibilita o desenvolvimento de atividades em campos de prática extra-hospitalares.

(A5) O limite de 40 horas semanais para realização de atividades do internato, aí incluídas no máximo 12 horas de plantão diárias, é uma tarefa possível de ser implantada.

(A16) O Contrato Organizativo da Ação Pública Ensino-Saúde (Coapes) tem se mostrado um meio simples para a pactuação de parcerias e aproximação ensino-serviço-comunidade. 
Verificou-se também que parte dos coordenadores não concorda com a recomendação das DCN de 2014 de que a preceptoria no internato médico deve ser exercida por profissionais do serviço de saúde, com supervisão dos docentes próprios das IES. Provavelmente, esse fato se deve ao reconhecimento da autonomia do profissional do serviço de saúde como preceptor na formação dos estudantes e à falta de docentes nos próprios cursos.

Dos coordenadores participantes, 46,1\% consideraram insuficiente o prazo-limite de 31 de dezembro de 2018 para a completa implantação das determinações das Diretrizes no internato médico. Diferentemente das DCN de 2014, as de 2001 não estabeleciam prazo para sua implantação.

Wanderley $^{5}$ considera que:

\begin{abstract}
É preciso que se considere também que a implementação de novas diretrizes curriculares não é um processo estático, apesar de garantido pela legislação, mas, ao contrário, é um processo dinâmico e acidentado, intercalado por avanços e retrocessos, que precisa ser cotidianamente construído nos diversos cenários de prática profissional, para o enfrentamento dos problemas que se apresentam na realidade. (p. 5)
\end{abstract}

Ainda sobre o VI Fórum de Ensino Médico, debateu-se que a elaboração das DCN de 2014 havia sido pouco democrática e que a normatização e o prazo para a sua implantação eram dificultados pela falta de consenso sobre suas determinações. Foi sugerida a ampliação do prazo para a implementação integral ${ }^{14}$.

Os coordenadores afirmaram que a carga horária semanal das atividades do internato representa até 40 horas semanais, e 12 deles referiram que os períodos de plantão compreendem até 12 horas por dia em conformidade com as DCN de 2014 e com a Lei do Estágio.

É importante observar que o internato representa a fase de profissionalização, em que existe maior aproximação da essência da prática médica, na qual ocorre o enfrentamento do discente com uma jornada de estudo/trabalho ampliada. Isto significa a aproximação do estudante de uma das características mais marcantes do trabalho médico: a intensidade do processo de trabalho, que contempla, geralmente, longas jornadas e múltiplas atividades simultâneas ${ }^{17}$.

Esse momento tem sido objeto de preocupação no sentido de se adequar a formação à jornada de atividades, incluindo os plantões. Querido et al. ${ }^{18}$, em estudo realizado em duas escolas médicas de Tocantins, identificaram que 52\% dos estudantes apresentavam estresse e, na maioria das respostas, indicavam como fatores desencadeadores o cansaço físico, a extensa carga horária de trabalho e o contato com ambientes e profissionais estressados.

Grande parte dos coordenadores (76,9\%) concorda em que o treinamento do interno em cenários de Atenção Básica e Urgência e Emergência deve representar, no mínimo, 30\% da carga horária total do internato, o que significa, pelo menos, seis meses nesses cenários. Afirmaram que seus cursos estão em consonância com as DCN de 2014 no que concerne a esta carga horária. No entanto, $61,60 \%$ deles afirmaram que é uma tarefa difícil de ser operacionalizada.

É importante observar que o início da vida profissional do médico tem, habitualmente, essas áreas de atuação profissional como principais oportunidades de emprego ${ }^{19}$. Uma pesquisa coordenada pela Fiocruz - "Perfil dos Médicos no Brasil" - mostrou que 70\% dos médicos brasileiros dedicam parte de sua carreira ao trabalho em urgência e emergência, principalmente nos anos iniciais da vida profissional ${ }^{17}$.

Em relação à carga horária total do internato, todos os participantes referiram que ela representa 35\% da carga horária total do curso, conforme preconizado pelas DCN de 2001 e reafirmado pelas DCN de 2014. Entretanto, na análise das questões abertas, foram identificadas escolas que ainda planejavam o internato com duração de dois anos, a partir do segundo semestre de 2018:

\section{[...] teremos o internato em dois anos a partir de 2018.2.}

[...] (estamos em fase de) implantação de novo currículo com duração do internato de dois anos.

Todos os coordenadores concordam em que as atividades voltadas à Atenção Básica devem ser realizadas no âmbito da Medicina Geral de Família e Comunidade e afirmam que, em suas escolas, essa recomendação está implementada, o que está em conformidade com as Diretrizes para o Ensino da Atenção Primária publicadas em 2012 pela Abem e Sociedade Brasileira de Medicina de Família e Comunidade ${ }^{20}$.

Dos coordenadores, 76,9\% concordam em que a Atenção Básica deve fazer parte do núcleo central das atividades discentes desenvolvidas no internato, posto que tem a capacidade de resolução de $80 \%$ dos problemas de saúde da população e deve representar a principal porta de entrada do usuário no sistema de saúde. Dessa forma, a inserção do estudante neste campo de prática mostra-se necessária para possibilitar a formação de profissionais com competências para atuar nesse contexto ${ }^{21}$.

As seguintes estratégias são apontadas para a implantação e reestruturação do ensino de Atenção Básica no internato: am- 
pliação e diversificação de cenários de prática específicos, como Clínicas da Família e Centro de Saúde da Família das Secretarias Municipais de Saúde, e desenvolvimento de atividades de Atenção Básica em interface com a Clínica Médica e Pediatria.

A inclusão obrigatória da área de Saúde Mental no internato tem a concordância de todos os coordenadores. Enfatizam que isto pode representar uma proposta de formação mais coadunada com as necessidades atuais da sociedade ${ }^{22,23}$. Apesar da concordância unânime, 46\% dos coordenadores afirmaram que suas escolas não possuíam atividades de Saúde Mental no internato médico até o momento da coleta de dados desta pesquisa. Vários indicaram a existência de uma programação para incluir essa área no internato:

[...] a Saúde Mental no internato já está programada, mas ainda estão sendo trabalhados os cenários e estratégias a serem adotados.

[...] (estamos) organizando programas e carga horária para adequar, a partir de 2017, a Saúde Mental.

Para a implantação e reestruturação do ensino de Saúde Mental no internato, apontam as seguintes estratégias: criação/ampliação de cenários de prática específicos, como Ambulatórios de Saúde Mental, visitas ao pronto-socorro psiquiátrico municipal, desenvolvimento de atividades em terapia comunitária e de família; abordagem transversal da Saúde Mental em todos os módulos do internato médico e implementação de atividades de Saúde Mental no âmbito da Atenção Básica.

Em relação às atividades de Urgência e Emergência, a maioria dos coordenadores $(84,60 \%)$ considera que elas devem ter destaque no internato, pois grande parte dos egressos inicia suas atividades profissionais nesses campos de prática. No entanto, conforme sinalizado pela Abem, "na quase totalidade das vezes, não há programa de ensino para emergências médicas na matriz curricular das faculdades de Medicina em nosso país" ${ }^{\prime 2}$. Uma proposta de implantação do ensino de Urgência e Emergência aparece em algumas escolas:

[...] a urgência e emergência no internato já está programada, mas ainda estão sendo trabalhados os cenários e estratégias.

Algumas estratégias para a implantação e reestruturação do ensino de Urgência e Emergência no internato foram apontadas: ampliação e diversificação de cenários de prática; ampliação de atividades de Urgência e Emergência com a criação de estágios eletivos, por meio de convênios com as emergên- cias da rede municipal; ampliação de atividades de Urgência e Emergência, com treinamento em laboratórios de simulação; desenvolvimento de atividades de Urgência e Emergência em Unidades de Pronto Atendimento do SUS.

As atividades em ambientes controlados (laboratórios de simulação) são atualmente consideradas fundamentais no desenvolvimento das atividades de Urgência e Emergência no internato. No entanto, somente $61 \%$ dos coordenadores referem utilizá-las como ferramenta para o desenvolvimento e treinamento das atividades práticas.

A opinião dos coordenadores mostra-se coerente com as recomendações das DCN de 2014, que, no capítulo I, seção III, Art. $7^{\circ}$, apontam a necessidade de o estudante "aprender em situações e ambientes protegidos e controlados, ou em simulações da realidade, identificando e avaliando o erro, como insumo da aprendizagem profissional e organizacional e como suporte pedagógico"7.

Como sinalizado no projeto "Abem 50 anos - 10 anos das Diretrizes Curriculares para o Curso de Graduação em Medicina", em seu subprojeto que avaliou a situação do ensino de Urgência e Emergência nos cursos de graduação em Medicina, das 54 escolas participantes, 70,4\% afirmaram oferecer atividades simuladas no internato ${ }^{2}$.

Aguiar et al. ${ }^{24}$ sinalizaram, no entanto, a subutilização desse importante recurso de ensino-aprendizagem em algumas escolas, justificada pelo elevado custo dos equipamentos utilizados para a reprodução dos diversos cenários e situações clínicas em Urgência e Emergência.

No que concerne às dificuldades/sugestões na operacionalização das determinações das DCN de 2014 no internato, os coordenadores apontam a precariedade dos cenários de Urgência e Emergência no âmbito do SUS. A não fixação dos profissionais nos serviços de urgência mostra-se um entrave ao desenvolvimento de atividades docentes nesse contexto. Dos coordenadores, 30,7\% consideraram impossível desenvolver atividades em cenários de Urgência e Emergência somente em serviços públicos.

Dos participantes, 31\% ressaltam que as atividades práticas de observação/assistência na área de Urgência e Emergência não são desenvolvidas, exclusivamente, em cenários do SUS, o que evidencia a impossibilidade do cumprimento integral das determinações das DCN de 2014, até o momento da realização da coleta de dados desta pesquisa.

Finalmente, a adoção de metodologias mais problematizadoras na abordagem teórica do internato apareceu como estratégia de adequação às DCN 2014. Os coordenadores apontaram diferentes possibilidades de operacionalização dessas metodologias, como: estudo de caso, desenvolvimento de ati- 
vidades que permitam integração multidisciplinar e utilização de novas tecnologias em ambiente virtual de aprendizagem.

Berbel ${ }^{25}$ ressalta que as metodologias ativas representam modos de desenvolver o processo do aprendizado com base em experiências reais ou simuladas, com o objetivo de solucionar problemas e superar desafios que emergem das práticas sociais em diferentes contextos. A autora cita Paulo Freire, que, em defesa das metodologias ativas, afirma que na educação de adultos o que impulsiona a aprendizagem é a superação de desafios, a resolução de problemas e a construção do conhecimento novo a partir dos conhecimentos e das experiências prévias dos indivíduos.

Entende-se que o internato médico, em sua essência, representa o que existe de mais concreto no que se refere às metodologias ativas na graduação médica, visto que as atividades de ensino-aprendizagem partem sempre do contato direto com a realidade, nos mais diversos cenários e contextos, nos âmbitos individual e coletivo; com a constante mobilização de conhecimentos prévios e o desenvolvimento contínuo do raciocínio clínico; e com o objetivo do encontro da solução oportuna dos mais variados problemas.

\section{CONCLUSÕES}

As escolas representadas passam por um processo de adequação para a implantação das DCN de 2014. Identificam-se muitas dificuldades na operacionalização das determinações contidas nessas diretrizes, em grande parte compartilhadas por vários participantes.

Algumas estratégias têm sido planejadas, como a diversificação dos cenários de prática, a criação de estágios eletivos, o estabelecimento de convênios e parcerias, o desenvolvimento de atividades integradas com outras áreas do internato e a utilização de laboratórios de simulação realística.

Algumas escolas ainda estão planejando o internato com duração de dois anos a partir do segundo semestre de 2018.

Não existe adequação integral em relação à determinação do cumprimento de $30 \%$ da carga horária do internato em atividades de Urgência e Emergência e Atenção Básica.

A inclusão de Saúde Mental no internato está presente apenas na metade das escolas, com dificuldades de criação de cenários específicos para esta prática.

Existe dificuldade de disponibilização de cenários específicos para o desenvolvimento das atividades de Urgência e Emergência, bem como obstáculos na realização de parcerias com os gestores municipais e estaduais. Foi apontada a possibilidade de desenvolver estas atividades em plantões de enfermaria, pronto-atendimentos e laboratórios de simulação, bem como a criação de estágios eletivos.
Houve reconhecimento do Coapes como uma possibilidade de avanço na ordenação de campos de prática para o internato. Todavia, foram indicadas dificuldades na execução dessas parcerias, evidenciando mais um entrave para o cumprimento das determinações contidas nas Diretrizes.

Existem dificuldades de supervisão pelos docentes das IES no que se refere à preceptoria no internato médico exercida por profissionais do serviço de saúde.

O prazo-limite estabelecido para a completa adequação às determinações contidas nas DCN de 2014 - final de 2018 - é considerado insuficiente.

Acredita-se que este diagnóstico possa auxiliar as escolas médicas no processo de apropriação e implantação das determinações das DCN de 2014. Ademais, estima-se que este momento de mudanças, impulsionado pelas Diretrizes, seja aproveitado como uma oportunidade para revisitar o internato médico e, possivelmente, encontrar estratégias para aprimorar a formação médica nesse espaço privilegiado da graduação.

\section{REFERÊNCIAS}

1. Conselho Federal de Educação. Resolução n ${ }^{\circ} 8$, de 8 de outubro de 1969. In: Araújo LS (org). Legislação do ensino superior; índice remissivo e jurisprudência. Rio de Janeiro: Renes; 1973.

2. Lampert JB, Bicudo AM. (Orgs.) 10 anos das Diretrizes Curriculares Nacionais do curso de graduação em Medicina. Rio de Janeiro: Associação Brasileira de Educação Médica; 2014.

3. Streit D, Maciel DT, Zanolli MB. Contribuição para a formação de Médicos de acordo com as necessidades da sociedade: interação com as políticas de articulação ensino serviço, sociedade implementadas pelo Ministério da Saúde. Cadernos ABEM. 2009;5:21-29.

4. Ministério da Educação (BR). Conselho Nacional de Educação, Câmara de Educação Superior. Resolução n ${ }^{\circ} 4$, de 7 de novembro de 2001: Institui Diretrizes Curriculares Nacionais do Curso de Graduação em Medicina. [Internet]. Brasília, 2001. Disponível em: http://portal.mec.gov.br/ cne/arquivos/pdf/CES04.pdf.

5. Wanderley VE. A Gestão Acadêmica na Reestruturação Curricular do Curso Médico: Uma Análise [tese]. São Paulo (SP): Universidade Federal de São Paulo; 2016.

6. Presidência da República (BR). Lei no 12.871, de 22 de outubro de 2013. Institui o Programa Mais Médicos, altera as Leis $n^{\circ} 8.745$, de 9 de dezembro de 1993, e n 6.932, de 7 de julho de 1981, e dá outras providências. Diário Oficial da União, 23 Out 2013. 
7. Ministério da Educação (BR). Conselho Nacional de Educação, Câmara de Educação Superior. Resolução n 3, de 20 de junho de 2014: Institui Diretrizes Curriculares Nacionais do Curso de Graduação em Medicina e dá outras providências. [Internet]. Brasília, 2014. Disponível em: http://portal.mec.gov.br/index.php?option=com docman\&view =download \&alias $=15874-$ rces003-14\&category_slug=junho-2014-pdf\&Itemid=30192

8. Gil AC. Como Elaborar Projetos de Pesquisa. 5 ed. São Paulo: Atlas; 2010.

9. Minayo MCS. O Desafio do Conhecimento: Pesquisa Qualitativa em Saúde. 14 ed. São Paulo: Hucitec Editora; 2014.

10. Gil AC. Métodos e Técnicas de Pesquisa Social. São Paulo: Atlas; 1987.

11. Mattar FN. Pesquisa de marketing. 6 ed. São Paulo: Atlas; 2005.

12. Franco MLPB. Análise do Conteúdo. 2 ed. Brasília: Líber Editora; 2005.

13. Ferreira BJ. Inovações na formação médica: reflexos na organização do trabalho pedagógico [tese]. Campinas (SP): Faculdade de Educação, Universidade Estadual de Campinas; 2004.

14. Conselho Federal de Medicina (CFM) e Associação Brasileira de Educação Médica. Consolidado do VI Fórum Nacional de Ensino Médico. Brasília; 2015.

15. Portaria Interministerial $n^{\circ} 1.124$, de 4 de agosto de 2015: Institui as diretrizes para a celebração dos Contratos Organizativos de Ação Pública Ensino- Saúde (COAPES), para o fortalecimento da integração entre ensino, serviços e comunidade no âmbito do Sistema Único de Saúde (SUS) [Internet]. 2015. Disponível em: http://portalarquivos. saude.gov.br/images/pdf/2015/outubro/23/COAPES-PORTARIA-INTERMINISTERIAL-N1.127\%20-DE-04\%20 DE-AGOSTO-DE-2015.pdf.

16. Gonzalez AD, Almeida MJ. Movimentos de mudança na formação em saúde: da medicina comunitária às diretrizes curriculares. Physis Revista de Saúde Coletiva. 2010;20(2):551-570.

17. Machado MH. Os médicos no Brasil:um retrato da realidade. Rio de Janeiro: Fiocruz Editora; 1997.

18. Querido IA, Naghettini AV, Orsini MRCA, Bartholomeu D, Montiel JM. Fatores Associados ao Estresse no Internato Médico. Rev Bras Educ Med. 2016;40:565-573.
19. Pereira Junior GA, Fraga GP, Arnaud F, Gula EA, Slullitel A, Garcia VL. O Ensino de Urgência e Emergência de acordo com as Novas Diretrizes Curriculares Nacionais e a Lei dos Mais Médicos. Cadernos ABEM. 2015;11:20-47.

20. Demarzo MMP, Almeida RCC, Marins JJN, Trindade TG, Anderson MIP, Stein AT, et al. Diretrizes para o Ensino na Atenção Primária à Saúde na Graduação em Medicina. Rev Bras Educ Med. 2012;36(1):143-148.

21. Batista NA, Vilela RQB, Batista SHSS. Educação médica no Brasil. São Paulo: Cortez Editora; 2015.

22. Ballester DA, Filippon AP, Braga C, Andreoli SB. The general practitioner and mental health problems: challenges and strategies for medical education. São Paulo Med J. 2005;123(2):72-76

23. Lei $n^{\circ} 10.216$, de 06 de abril de 2001. Dispõe sobre a proteção e os direitos das pessoas portadoras de transtornos mentais e redireciona o modelo assistencial em saúde mental. Diário Oficial da União, 09 Abr 2001.

24. Aguiar HDG, Dias VL, Lage LF, Madad Filho A, Gama PO, Gonzaga DM et al. O ensino da medicina de urgência no Brasil. Rev Med Minas Gerais. 2011;21(4):27-31.

25. Berbel NAN. As metodologias ativas e a promoção da autonomia de estudantes. Semina: Ciências Sociais e Humanas. 2011;32(1):25-40.

\section{CONTRIBUIÇÃO DOS AUTORES}

Patricia Tavares da Silva Candido contribuiu na identificação do problema, coleta e análise dos dados e redação do artigo. Nildo Alves Batista orientou, contribuiu na metodologia, análise dos dados e revisão da redação do artigo.

\section{CONFLITO DE INTERESSES}

Não há conflito de interesses.

\section{ENDEREÇO PARA CORRESPONDÊNCIA}

Av. Barão do Rio Branco, 1003

Centro - Petrópolis-RJ

Faculdade de Medicina de Petrópolis

CEP: 25680-120

E-mail: patricia@fmpfase.edu.br 